\title{
On Graduate Students-centered English Teaching based on PBL in the Big Data Era
}

\author{
HuiQin ZHANG* \& JunMin WU \\ Department of Foreign Languages, Beijing Institute of Fashion Technology, China
}

\begin{abstract}
The coming of the big data era and the needs of the innovative talents require students-centered teaching in different fields, cultivating the graduates' ability in discovering problems, analyzing the problems and solving the problems. The paper illustrates the graduate students-centered English teaching practiced in one of the Arts Universities in Beijing as an example, focuses on four points, including how to renew the teaching idea, enrich the teaching content, reform the teaching methodology and evaluation system so that to meet the society's needs, and at the same time focuses on the ways to promote the graduate students English ability both in practice and academic research.
\end{abstract}

KEYWORD: big data; PBL, students-centered; creative

\section{INTRODUCTION}

With the development of education, the perfection of digital English teaching resources and teaching platform makes the students' English learning progress under teachers' control in the form of big data. Students' progress can be concluded from unit test results and the problems exposed, etc.. At the same time, supporting teaching resources like convenient electronic dictionaries and movie clips related to the text background make English teachers pay more attention to, have more trust in, and even have more dependence upon big data. The concept of PBL (problem-based-learning) originated in the 1950s and based on "students-centered" in medical education has been popular internationally. How to rely on the background of the big data, and explore graduate students-centered English teaching based on PBL gradually draw the attention of many colleagues. The paper illustrates the graduate students-centered English teaching practiced in one of the Arts Universities in Beijing as an example, and explores graduate English teaching reform research and practice based on PBL "studentcentered" in the big data era.

\section{THE DEFINITION OF THREE CORE CONCEPTS: BIG DATA, PBL AND "STUDENTS-CENTERED" ENGLISH TEACHING}

The concept of "big data" comes from the worldrenowned McKinsey Company, and treated as an important production factor in different fields today. People are mining and utilizing huge amounts of data, which heralds the increase of production rate and the arrival of consumer surplus. Guo Xiaoke, 2013:5) Researchers of US Internet Data Center define the "big data" as a kind of new technical architecture, which is capturing value from the capacity of data through high-speed capture, discovery and analysis. Its connotation can be summarized as the four V English letters(volume, variety, velocity, and value). (Zhang Yannan \& Zhao Zhongjian, 2013: 5) The advent of the big data era means the unprecedented convenience for the sharing of English teaching resources, giving the monitoring and implementation of autonomous learning so that to improve the evaluation of teaching. And the big data Era also provides the technical support for students-centered English teaching based on PBL.

PBL (problem-based-learning) originated in the 1950s in medical education, which has now become one of the terms in Language teaching. The key point of this method is to set students to a complex situation, promote students' ability of autonomous learning and practical problems solving through learners' autonomous learning and cooperation with each other. Compared with the traditional teaching, PBL emphasizes that the learners should be responsible for their own learning tasks. And it can improve learners' ability of autonomous learning and of problems solving by integrating a variety of learning methods and putting themselves into practice.

According to the definitions and explanations of 
these three concepts, and the requirements of our national "graduate English syllabus", the purpose of graduate English teaching is to make students master generally English knowledge so as to acquire professional knowledge, do research and communicate internationally, and to serve our country in the future. Liu Yandong gave an address on the 30th "Graduate Education and the Academic Degrees Committee of the State Council Session", just as she said, the graduate student education should take serving the demand of our country as the guidance, regard improving the training quality as the core, optimize the size, the layout and the discipline structure, and adhere to the hierarchical education and character development. It should promote the reform of education mode in classification, implement knowledge learning and ability training, pay equal attention to strengthen the graduate students' sense of social responsibility, scientific spirit and innovative practice ability, and improve the training quality. There should be the education reform pattern including a set of recruitment, training and evaluation system. (http://tv.people.com.cn/n/2013/0711/c61600-22162 409.html) Teachers should adhere to the principle of "study and practice", to cultivate and improve students' ability to use English. (http://yjsc.lcu.edu. $\mathrm{cn} /$ ShowArticle.asp?ArticleID=52) English teaching under the digital background must reform to meet the students' double requirements of knowledge learning and ability training.

\section{PRACTICE ON GRADUATE STUDENTS- CENTERED ENGLISH TEACHING BASED ON PBL IN THE BIG DATA ERA}

\subsection{Renewing the Teaching Concepts and Enriching the Teaching Contents}

In graduate English teaching, "student-centered" should be the key point, teachers are supposed to respect students and adjust their teaching based on the actual needs of students. During the first class, the teacher should give a brief self-introduce about his or her academic experience, academic orientation and ongoing research projects, especially the social value and significance of the research in order to enhance the understanding from the students, and also inspire students to think how to participate in the teacher's research project. At the same time, students will begin to think about the reason why they choose to pursue the master's degree and the specific goals they are going to achieve. Then the teacher should introduce the learning content of this term to the graduates, namely the graduate English integrated course (paper textbooks from Foreign Language Teaching and Research Press) and network autonomous learning course "academic connections 3", and explain the reason why to choose these two materials at the same time. During the period of graduate season, art students might go out frequently to capture inspiration and prepare for exhibitions to enhance their comprehensive development, through the network at anytime, rather than mandatory attendance as before. Teachers can check student's learning and trace feedback through the teaching platform offered by internet, and such result is the important basis to evaluate their daily performance.

On condition that students get clear about teaching purpose and teaching material, they will reach a consensus with the teachers. The writer makes use of network resources under the background of big data, collect internet material (13th president of Princeton University Woodrow Wilson's speech) as the supplementary reading of the Unit 10 (The Role of the Academic in Times of Crisis) in the paper textbooks, and present students in the form of PPT.

At the same time, teachers can guide students in using network resources, looking up the websites of famous universities in the world, such as Princeton University, Harvard University, University of the Arts London, Paris College of Art, University of Manchester, City University of Hong Kong, and so on. Teachers can search other university's information about graduate education and compare with our graduate student curriculum and training mode, then think about the possible gaps with the international standard. Students are required to form groups and look through the introduction of foreign college English website to cultivate cooperative consciousness, expand knowledge and even broaden the students' view. The complement of the textbook materials and network resources makes the teaching content more relevant to the students' actual demands, improves the effectiveness of language learning, and is more suitable for graduate students' learning needs. In fact, only by focusing on the teaching contents, constantly updating, enriching and perfecting the teaching contents with modern technology, and paying attention to the data analysis, can teachers launch in-depth exploration on a certain subject, and maintain students' lasting appeal and true participation.

\subsection{Innovating Teaching Methodology and Propelling Evaluation Means}

It is the basis of teaching methodology innovation to change the teaching philosophy, constantly enrich teaching content in the big data era, and combine dynamic network resources with the textbook. After importing the text, the teacher may ask students to search for the website they are interested in. In order to inspire students to look at the problem from a different aspect, and develop their critical thinking, students will be asked to collect and analyze the speeches of university presidents on the graduate opening ceremony, and then they need to upload the 
materials to share resources together. For instance, president of Tsinghua University stresses the interest in scientific research, research power and scientific innovation; Nankai University's president starts with taking courses, choosing topics, doing research or presenting achievements, and highlights the challenges students are going to face up and even the school motto "Discipline, Practicality, Unity and Creativity ", so that to encourage students to have a sense of social responsibility and get innovation; while explaining the importance of communicating with international education, president of East China University of Technology requires students to be innovative.

Graduates generally have a better understanding of studying, but they also need a set of rational systems. Students need to do at least one lesson's homework each week on the internet, and report their questions through QQ to the monitor before class. Then the teacher will make comments on the questions according to their different levels, then inspire, guide and question students to think and discuss the problems in the classroom, and solve the problems by themselves. This process includes locking the questions clues, understanding the key point, and finding out solution, and sometimes even involves consulting a dictionary, consolidating the grammar knowledge and interpreting the cultural differences. At the same time, teachers should make full use of modern technology; input the student name and study number directly into the teaching platform, create an electronic file, and be ready to disclose the learning process. For example, the teacher may assign the homework, and students are required to query data. Teachers may access to the student electronic portfolio at any time, give the reviews and bonus to good resources and good videos the students collected, and encourage the class to share resources to develop a sense of accomplishment, get to know their learning goals and complete the research project by constantly checking their learning portfolios. As for students who can not attend the class for various reasons, they can choose to learn through the network to make it up. Teachers should encourage students to increase the amount of network learning, collect resources according to their research interests, and learn English by different channels. All the learning processes of each student is under teacher's control, and the whole class learning progress can be shown to the students in the form of big data. Formative assessment takes up $50 \%$ of the total score, which includes online learning tasks (30\%), classroom performance $(5 \%)$, network writing $(10 \%)$, and group work $(5 \%)$, and summative assessment accounts for $50 \%$ of the total score, which is the unified proficiency test at the end of each semester. The author is pleased to see that, either early 4:00am or late 12:00pm, whether in the dormitory or outside in the hostel, there are always students learning independently through the internet.

\subsection{Making Use of Local Materials and Improving Students' English Practical Ability through Various Channels}

After finishing unit 10, the teacher inspires students to search the combination of teaching experience and academic research from the school website. Students will find that the Doctor Programs, Major Project of Humanities and Social Science on Arts, international friends, and even the UNESCO officials are associated with the traditional national costumes in the museum. The Dunhuang Art Exhibition and South Korea "Mother's Fragrance" Patchwork Art Exhibition, and Chinese Culture Creations are frequently exhibited in BIFT Park. All the information makes students come to understand that both the Ethnic Costume Museum and BIFT Park are the carrier of fusion of teaching and research, and university's research requires students to have higher English levels. On condition that students understand the importance of learning English, teachers will organize "English Corner" activity in the university's cafe, to discuss topics like campus cultural life, cultural differences in fashion between Chinese and Western, and international education. English teachers, foreign teachers and graduates will participate in. At the same time, teachers should take advantage of the costumes cultural resources in the museum. They can organize students to learn about the English-Chinese interpretation of the museum collections, and to act as the English docents for the Ethnic Costume Museum, in this way, students can not only know better about Chinese culture, but also enhance national self-confidence and social responsibility. To interpret the clothing exhibition in the BIFT Park that combines tradition with modern is a challenge for students, which can also cultivate graduate students to be creative and capable. Practice has proved that English practice like this can make students enhance the understanding of Chinese culture, and become more confident in traditional culture. Graduates in the direction of Chinese and western clothing culture in the Department of Foreign Languages tried to buy mulberry silk, watered gauze fabrics and all kinds of leather on line, then they designed clothes and accessories. By way of cooperation, they made leather handbags, silk scarves, exquisite traditional necklaces and bracelets, improved cheongsam, etc., all these can be seen in the BIFT Park and Aegean Sea Shopping Center in Beijing, and consumers even call students to order these well-designed works. Since graduate students often take part in all kinds of academic conferences and exhibitions in their spare time, the author inspires the students to focus on the needs of dress and encourage them to do a research on the dress of female teachers at colleges and universities in Beijing. And then give students timely guidance and help, finally the investigation report will be published in academic journals. 
Constantly accumulation to make graduate students' study is more colorful in practice. Students form different majors should fuse knowledge and innovation according to their own needs, career objectives and development orientation, try to apply their knowledge into use, so that they can get the recognition from the market and society. Most of the majors have good enrollments, the university's has gained better comments year by year, and the number of national projects and innovative works is doubled than that of the before.

\section{REFLECTION AND INSPIRATION ON GRADUATE ENGLISH TEACHING PRACTICE}

Graduate English teaching reform experience in the big data era requires teacher to spare no efforts to focus on students, help students discover and solve problems, achieve the integration of teaching and research. First of all, teachers must have the courage to face the challenges of new technologies, such as using the platform, tracking the students' learning process. All these make teachers to discover the students' problems indicated in the learning data. At the same time, teachers should try to help students solve problems by taking some measure, avoid generalization or even "consider the data only instead of the students." Secondly, while organize the classroom discussion and stimulate students' thinking, teachers must behave properly and deal with problems according to the reality flexibly, giving students enough freedom to think. Meanwhile, teachers can also take every unit as a research subject, research from different perspectives, and inspire students to deal with academic issues seriously. Students can give the present of each unit with group collaboration, and each student can serve as the representative to elaborate in a limited period of time. Gradually, students will adapt the international academic programs much better for their bright future, and make preparations for their future participation in international academic conferences. In addition, teachers can also try to simulate the international conference on academic research by inviting foreign teacher to teach the same class with them, or invite experts from other foreign universities to give lectures on special topics. Such practice is a challenge for English teachers to spare no efforts to be educated.

\section{CONCLUSION}

The arrival of big data era, the international standards of graduate education goals, and the global demand for innovative talents, require graduates to gain the ability in discovering and solving problems, and to be responsible for all disciplines in training and education of graduate students. English teaching should not only build up the bridge between Chinese and western cultures, but also make innovation in teaching philosophy, teaching content, teaching methodology and evaluation system, so that English learning can really become the link to help graduate student acquire knowledge, develop scientific spirit, innovate research ideas and enhance the scientific research. Different universities have their own different distinguished programs, which affects the choices of teaching methodology to some extent. As long as teachers work hard to accept the challenges of the era, conduct the students-centered English teaching based on PBL (problem-based-learning) concerning the actual needs of the students, graduate English teaching will gain success in the integration of teaching and research.

\section{ACKNOWLEDGEMENT}

The research is sponsored by the project "graduate English teaching reform in the context of International" [QTXM02140201/013], the paper is one part of the research result.

\section{REFERENCES}

[1] BARR. RB, TAGGJ, From Teaching to learning-A New Paradigm for Undergraduate Education.Change,pp.1315,1995

[2] Guo Xiaoke, Big Data, Beijing:Tsinghua University Press , 2013.

[3] He Xiaolan, College Students-Centered English Teaching. China University Teaching, 12(7), pp. 36-37, 2010.

[4] Chen Jinping, College English Teachers' Professional Development in the Big Data Era. Contemporary Foreign Language Study, 12(4), pp. 35-38, 2014.

[5] Zhang Yannan \& Zhao Zhongjian, The Enlightenment Big Data Era Thinking Mode Has on Education. Research in Education Development, 24(21), pp. 1-5, 2013.

[6] Xiong Haihong, Graduate English Integrated Course, Beijing: Foreign Language Teaching and Research Press, 2013

[7] Graduate English Teaching Syllabus, State Education Commission.http://yjsc.lcu.edu.cn/ShowArticle.asp?Articl eID $=52$

[8] Archived Site: Office of the President, Shirley M. Tilghman.

http://www.princeton.edu/president/tilghman/pages/20011 024/

[9] Teaching Method Based on PBL (problem-based-leaing). http://www.chinadmd.com/file/o3e66psxxi3ueivrreeavicw 1.html

[10] Liu Yandong Attend the 30th "Graduate Education and the Academic Degrees Committee of the State Council Session".http://tv.people.com.cn/n/2013/0711/c6160022162409.html

\section{AUTHOR}

Huiqin Zhang, Dr. graduated from Shanghai International studies University, the professor of Beijing Institute of Fashion Technology, orientation is applied linguistic, translation study, fashion and culture. 